\title{
A polissemia da palavra "Experimentaçãa" e a Educação em Ciências
}

\section{The polysemy of the word "experimentation" and the Science Education}

\author{
Rafael Cava Mori e Antonio Aprigio da Silva Curvelo
}

\begin{abstract}
Resumo: $\mathrm{O}$ artigo analisa a polissemia da palavra experimentação no contexto da Educação em Ciências, a partir da filosofia da linguagem expressa em obras do chamado "Círculo de Bakhtin". Primeiramente, são discutidos os conceitos de tema e de significação, conforme definidos por Voloshinov. A seguir, faz-se o levantamento de um material empírico, consistindo no conjunto de significações correntes da palavra experimentação (e palavras derivadas), conforme registradas em dicionários. A partir desse material, sugere-se uma estrutura para o conceito de experimentação, consistindo na proposta de três domínios semânticos cujos conteúdos concorrem para a significação dessa palavra. Um breve estudo histórico mostra como esses domínios são preenchidos por diferentes conteúdos ao longo da trajetória do ensino das ciências. Finalmente, considerando a historicidade dessa estrutura do conceito em investigação, aventam-se possibilidades para estudos futuros, tomando-se em consideração as relações entre experimentação no ensino e tendências pedagógicas, sejam elas hegemônicas ou contra hegemônicas.
\end{abstract}

Palavras-chaves: experimentação no ensino. Filosofia da linguagem. Círculo de Bakhtin. Tema e significação. Epistemologia. Pedagogias críticas.

\begin{abstract}
This paper analyses the polysemy of the word experimentation, in the context of Science Education, according to the philosophy of language expressed in works of the Bakhtin's Circle. After discussing the concepts of theme and meaning as defined by Voloshinov, a survey of empirical data is presented, consisting of meanings of the word experimentation, and of derived words, as recorded in dictionaries. It is suggested from the survey a structure for the concept of experimentation composed by three semantic areas whose contents contribute to the meaning of the word. A brief historical study shows how these semantic areas are filled by different contents along the trajectory of science teaching. Finally, given the historicity of this structure, which is proposed for the concept of experimentation, some possibilities for future studies are suggested, addressing the relations between experimentation and pedagogical trends (hegemonic or counter-hegemonic).
\end{abstract}

Keywords: experiments in Science teaching. Philosophy of language. Bakhtin Circle. Theme and meaning. Epistemology. Critical pedagogies.

Rafael Cava Mori (rafael.mori@ufabc.edu.br), bacharel e licenciado em Química pela Universidade de São Paulo, mestre e doutor em Físico-Química pela mesma instituição, é professor do Centro de Ciências Naturais e Humanas, da Universidade Federal do ABC. Santo André, SP - BR. Antonio Aprigio da Silva Curvelo (aprigio@iqsc.usp.br), bacharel em Química pela Universidade de São Paulo, doutor em Química Orgânica pela mesma instituição, é professor titular do Instituto de Química de São Carlos da Universidade de São Paulo. São Carlos, SP - BR.

Recebido em 06/01/2017, aceito em 02/04/2017

A seção "Cadernos de Pesquisa" é um espaço dedicado exclusivamente para artigos inéditos (empíricos, de revisão ou teóricos) que apresentem profundidade teórico-metodológica, gerem conhecimentos novos para a área e contribuições para o avanço da pesquisa em Ensino de Química. 
Entre os referenciais adotados na pesquisa educacional, os estudos associados ao nome do soviético Mikhail Mikhailovich Bakhtin (1895-1975) vêm se tornando cada vez mais frequentes. Freitas (1994), investigando o aportar de suas ideias - e também de Lev Semionovitch Vigotski (1896-1934) - no Brasil, afirma que isso aconteceu a partir dos anos 1970, graças a pesquisadores das áreas de Psicologia, Letras e Educação. Freitas lembra também que a difusão dos nomes desses intelectuais, em nosso território, esteve relacionada com a história política brasileira, em um momento de enfraquecimento do regime ditatorial civil-militar que esteve no poder entre 1964 e 1985. Esse período foi marcado pela valorização, no Brasil, de perspectivas críticas tanto ao escolanovismo, quanto aos autores franceses "reprodutivistas" (como Althusser e Bourdieu). Tais perspectivas, inspiradas em uma visão de mundo democrática e socialista, reconheciam a escola como arena de contradições, com a função de socializar o saber elaborado historicamente pela humanidade.

Em geral, os trabalhos que tomam as obras de Bakhtin como referencial, no campo da Educação em Ciências, se apoiam no conceito de enunciado, e em conceitos decorrentes ou associados a este (como gênero, acabamento, respondibilidade, dialogismo e polifonia), para discorrer sobre ou analisar a questão da linguagem em situações didáticas. Um exemplar desse tipo de estudo é o artigo já clássico de Mortimer e Scott (2002), em que tais conceitos servem à construção de uma ferramenta analítica de interações discursivas em sala de aula. Subjacente às considerações dos autores está a definição do enunciado como unidade mínima do discurso, caracterizado por um acabamento que permite/exige resposta do interlocutor. A linguagem é tratada, assim, como inerentemente dialógica, apesar de haver gêneros de discurso em que tal característica adquire maior importância. Finalmente, consideram os autores que o professor deve revezar adequadamente esses gêneros, lançando mão de discursos ora mais, ora menos dialógicos, para potencializar a formação de conceitos científicos por parte dos estudantes.

Neste trabalho, veremos como um referencial teórico que articule as obras do chamado "Círculo de Bakhtin" pode auxiliar a nós, educadores em ciências, a compreender os próprios conceitos que utilizamos em nosso campo do conhecimento.

O conceito escolhido para essa análise, a partir da filosofia da linguagem associada ao nome de Bakhtin, será a experimentação no ensino. Como veremos, a palavra experimentação aparece envolta em uma polissemia, implicando em diferentes modalidades de trabalho experimental para a educação científica. Realizaremos uma investigação da gênese dessa polissemia, marcada pelo surgimento, em diversas etapas históricas da experimentação, de vozes (por vezes, conflitantes) que ressoam no interior dessa palavra.

Primeiramente, discutiremos os principais conceitos "bakhtinianos" mobilizados em nossa análise, tema e significação. A seguir, apresentaremos o material empírico que servirá à apreensão de uma possível estrutura para o conceito de experimentação. A historicidade dessa estrutura será estabelecida narrando-se a trajetória da atividade experimental. Isso possibilitará, em conclusão, aventarmos possibilidades tanto para a continuidade deste trabalho quanto para repercussões nas práticas pedagógicas.

Argumentaremos que, a partir desse estudo semântico-histórico, "escavando" as sucessivas camadas de significados depositadas na palavra, será possível caminhar em direção aos seguintes objetivos:

a) esclarecer aspectos da própria conceituação da experimentação didática;

b) a partir de tais esclarecimentos, orientar uma agenda de pesquisa que articule a experimentação com perspectivas pedagógicas contra-hegemônicas, ou que ainda não têm despertado suficiente atenção por parte dos educadores.

\section{Tema e significação}

Os conceitos tema e significação são detalhados na obra Marxismo e filosofia da linguagem, no Brasil, livro-chave e ponto de partida para a compreensão de todo o corpus "bakhtiniano" (Freitas, 1994). Antes de caracterizarmos tais conceitos, convêm alguns esclarecimentos concernentes à autoria e condições de produção desse livro.

Marksizm i filossófia iaziká foi publicado em 1929, sob o nome de Valentin Nikolaevich Voloshinov (1895-1936). A obra divide-se em três partes. A primeira e a segunda realizam uma espécie de estado da arte da filosofia da linguagem, constatando a existência de duas orientações de pensamento (o subjetivismo idealista e o objetivismo abstrato - cujo representante de maior prestígio, à época, seria Saussure). Já a terceira busca aplicar o "método sociológico" à análise do discurso literário, a partir de uma teoria de base marxista superadora das duas correntes em litígio.

Na elaboração desse enfoque para o estudo da linguagem uma poética sociológica -, Voloshinov propõe alguns conceitos que mencionamos na seção anterior, sendo o mais importante, a nosso entender, o de enunciado. Para o autor, a filosofia da linguagem, até então, tratara de unidades de análise arbitrárias e abstratas, como a oração e a palavra, cindindo o estudo das línguas com a contraposição de sua dimensão formal a seu uso comunicativo. Com o conceito de enunciado, é possível estudar a linguagem de um ponto de vista histórico e dinâmico, ao contrário do idealismo e do formalismo, que a imobilizaram como uma espécie de língua morta. $\mathrm{O}$ enunciado permitiria apreender a linguagem viva, não apartando a análise científica de seu emprego nas trocas verbais.

Enquanto que, nos anos seguintes à edição da obra, a autoria de Marxismo e filosofia da linguagem não fora contestada, a partir dos anos 1970 Vyacheslav Vsevolodovich Ivanov (1929-) difundiu a informação de que o livro pertenceria a Bakhtin, e não a Voloshinov. Tal reviravolta causou rebuliço 
na comunidade acadêmica, ao ponto de edições mais recentes do livro serem creditadas apenas a Bakhtin ou a "Mikhail Bakhtin (Voloshinov)", como no caso da edição brasileira. Não iremos adentrar na polêmica dos chamados "textos disputados" de Bakhtin. Entendemos que a obra Bakhtin desmascarado (Bronckart; Bota, 2012) reúne argumentos suficientes para reestabelecer a autoria de Marxismo e filosofia da linguagem a Voloshinov, e sugerimos que o leitor interessado leia integralmente esse verdadeiro dossiê a respeito das controvérsias que envolvem o nome de Bakhtin.

Objetos do capítulo 7 ("Tema e significação na língua"), da segunda parte de Marxismo e filosofia e da linguagem, os conceitos tema e significação são apresentados enquanto pares dialéticos fundamentais para a comunicação verbal.

O tema se refere ao que é individual, instável e não reiterável no processo comunicativo; a significação, ao contrário, é consensual, estável e reiterável. O tema está para o enunciado, unidade concreta da comunicação verbal, assim como a significação está para as palavras e orações, unidades abstratas e convencionais da língua. Nas palavras do autor,

O tema da enunciação é na essência irredutível a análise. A significação da enunciação, ao contrário, pode ser analisada em um conjunto de significações ligadas aos elementos lingüísticos que a compõem [...]. O tema é um sistema de signos dinâmico e complexo, que procura adaptar-se adequadamente às condições de um dado momento da evolução [da língua]. O tema é uma reação da consciência em devir ao ser em devir. A significação é um aspecto técnico para a realização do tema (Bakhtin, 2004, p. 129).

Para Voloshinov, tema e significação são inseparáveis e não possuem fronteiras. Trata-se de dois aspectos do que o autor chama de "capacidade de significar": o tema, seu estágio superior, real; a significação, o estágio inferior e apenas potencial. Consideramos que o tema possa ser aproximado do conceito de sentido, como exposto por outro estudioso soviético, Aleksei Nicolaevitch Leontiev (1903-1979), na obra O desenvolvimento do psiquismo. Para esse pensador, se o significado (ou a significação) se refere a algo fixado historicamente em determinado signo através de repetidos usos na comunicação social, o sentido, ao contrário, possui natureza pessoal. Além disso, acrescenta Leontiev, a dicotomia significado social/sentido pessoal é uma implicação das relações sociais de produção de nosso tempo histórico, quer dizer, emerge do processo de separação entre trabalhos manual e intelectual (Leontiev, 1978) - tese que, no entanto, não é explorada na obra de Voloshinov.

Podemos resumir as considerações acima dispondo os principais conceitos associados ao "Círculo de Bakhtin" enquanto pares dialéticos (Quadro 1). A significação se refere a uma propriedade historicamente atribuída aos signos linguísticos, sendo consensual e universalmente aceita; subordina-se às relações lógicas, formais, que arbitram a constituição da língua enquanto instrumento para a comunicação verbal. O tema, por outro lado, diz respeito às situações concretas de uso da língua, que são irrepetíveis, pois incorporam no sistema linguístico elementos contextuais que ultrapassam a capacidade abstrata de significar. As palavras e orações que, enquanto unidades abstratas da língua, só podem ser analisadas conforme categorias lógicas (identidade, negação, terceiro excluído), são insuficientes para a apreensão da realidade dos fenômenos linguísticos. Estes, organizados pelas trocas discursivas entre enunciados concretos, elos na cadeia da comunicação verbal inerentemente dialógica, exigiriam para seu estudo uma ciência igualmente concreta, para além da linguística e suas categorias abstratas - uma metalinguística, como defende Bakhtin (1981).

Quadro 1: Conceitos associados ao Círculo de Bakhtin, em interação dialética.

\begin{tabular}{|cc|}
\hline significação/significado & tema/sentido \\
\hline estável & instável \\
reiterável & não-reiterável \\
consensual & pessoal \\
universal & contextual \\
potencial & real \\
língua & fala \\
palavra/oração & enunciado \\
lógico & dialógico \\
linguística & "metalinguística" \\
abstrato & concreto \\
\hline
\end{tabular}

\section{Significados de experimentação}

Quais as repercussões que esses conceitos podem trazer para a investigação científica? É o próprio Voloshinov quem responde:

A investigação da significação de um ou outro elemento lingüístico pode, segundo a definição que temos, orientar-se para duas direções: para o estágio superior, o tema; nesse caso, tratar-se-ia da investigação contextual de uma dada palavra nas condições da enunciação concreta. Ou então ela pode tender para o estágio inferior, o da significação; nesse caso, será a investigação da significação da palavra no sistema da língua, ou em outros termos a investigação da palavra dicionarizada (Bakhtin, 2004, p. 131, grifo nosso).

Em outro momento de Marxismo e filosofia da linguagem, Voloshinov já mencionara uma heurística da investigação sobre a palavra na concretude da vida, e sobre a contradição 
fundamental que a atravessa, a saber, seu aspecto simultaneamente uno e múltiplo:

\section{O sentido da palavra é totalmente determinado} por seu contexto. De fato, há tantas significações possíveis quanto contextos possíveis. No entanto, nem por isso a palavra deixa de ser una. Ela não se desagrega em tantas palavras quantos forem os contextos nos quais ela pode se inserir. Evidentemente, essa unicidade da palavra não somente é assegurada pela unicidade de sua composição fonética; há também uma unicidade inerente a todas as suas significações. Como conciliar a polissemia da palavra com sua unicidade? É assim que podemos formular, de modo grosseiro e elementar, o problema fundamental da semântica. Esse problema só pode ser resolvido pela dialética (Bakhtin, 2004, p. 106, grifos nossos).

Tais considerações vão ao encontro de inquietações nossas a respeito da polissemia que caracteriza o conceito de experimentação no ensino, um dos mais importantes e específicos da área de Educação em Ciências. De fato, há diferentes enfoques e finalidades para o que se chama de atividade experimental didática (Araújo; Abib, 2003), frequentemente conduzindo a equívocos e confusões entre o que seriam trabalhos práticos, experimentos no ensino de ciências e experimentos na ciência (Hodson, 1988).

Restringir nossos esforços à palavra experimentação enquanto categoria abstrata não seria um caminho para se esclarecer o problema de sua polissemia. Afinal, um dos projetos do "Círculo de Bakhtin" seria o de pensar o signo para além do domínio da língua, considerando-o no domínio do discurso (e, assim, da vida) e concebendo-se que a palavra é interindividual e ressoa as vozes de todos que a utilizam/utilizaram historicamente (Cereja, 2012).

Para se identificar essas vozes, no entanto, um ponto de partida precisa ser eleito. Tal ponto de partida não pode, por evidentes razões de ordem prática, ser o próprio emprego da palavra experimentação na vida, enquanto enunciado concreto dos falantes que a tomam. Sob a perspectiva dialética - segundo Voloshinov, o único caminho frutífero para tal empreitada investigativa -, partir do concreto é uma impossibilidade em termos metodológicos, o que já fora inclusive evidenciado por Marx na "Introdução" da Contribuição à crítica da economia política (Marx, 2013). Sobre essa questão, explica Saviani (2012b) que o movimento do conhecimento compreende dois momentos:

i) partindo-se do empírico (forma sincrética, caótica, confusa como o objeto se apresenta à contemplação imediata), emprega-se a análise para a elaboração do abstrato (constituído por conceitos, relações e determinações mais simples); e

ii) partindo-se do abstrato, emprega-se então a síntese para reconstituir o objeto concreto (agora, entendido como uma rica totalidade de determinações e de relações numerosas).
Caberia então identificar primeiramente um material empírico que pudesse nos guiar às categorias abstratas relacionadas à palavra experimentação. Considerando a passagem de Voloshinov que reproduzimos há pouco, consideramos que os dicionários podem oferecer esse material empírico, dado que seu objetivo é identificar e registrar os usos consagrados das palavras. Assim, podemos realizar uma análise da palavra experimentação a partir de seu registro dicionarizado, operando uma verdadeira dissecação de seu conteúdo semântico. ${ }^{1}$

Para iniciar esse trabalho, então, pesquisamos os verbetes experiência, experimentação, experimentar e experimento em três dicionários de língua portuguesa, Houaiss (Koogan; Houaiss, 1997, p. 650-651), Michaelis (Michaelis, 1998, p. 923) e Aurélio (Ferreira, 1999, p. 862).

$\mathrm{O}$ verbete experiência, nos três dicionários, aparece com significados práticos: prática de vida, vivência, "É homem vivido, cheio de experiência" (Aurélio). Essa dimensão prática frequentemente é exposta por uma óptica mais epistemológica: "Conhecimento adquirido pela prática da observação ou exercício" (Houaiss), "Conhecimento adquirido graças aos dados fornecidos pela própria vida [...] Conhecimento das coisas pela prática ou observação" (Michaelis). A caracterização prática da experiência também está presente nas definições do verbete experimentar: pôr em prática, executar, conhecer por experiência.

O lado prático da experiência também possui uma dimensão técnica, com conotação mais mecanizada, quase involuntária: "Habilidade, perícia, prática, adquiridas com o exercício constante de uma profissão, duma arte ou ofício" (Aurélio), "Perícia, habilidade que se adquirem pela prática" (Michaelis). O mesmo pode ser dito quanto ao verbete experimentar: para o Aurélio e o Michaelis, pode ser o mesmo que adestrar (-se).

A dimensão filosófica da experiência aparece somente no Aurélio: "Conhecimento que nos é transmitido pelos sentidos", "Conjunto de conhecimentos individuais ou específicos que constituem aquisições vantajosas acumuladas historicamente pela humanidade". A primeira dessas definições apresenta a corrente de pensamento conhecida como empirismo, para a qual todo conhecimento parte das impressões sensoriais, inexistindo dados a priori na mente humana. Veremos adiante a importância do empirismo (e de sua superação) para a experimentação no ensino de ciências.

Finalmente, a experiência é caracterizada nos três dicionários como um objeto da cultura científica: "Ensaios, tentativas para verificar ou demonstrar qualquer coisa" (Houaiss), "Ensaio prático para descobrir ou determinar um fenômeno, um fato ou uma teoria; experimento, prova" (Michaelis). O Aurélio chega a exemplificar: experiência química.

Estas últimas definições darão o tom àquelas dos verbetes experimentação e experimento, postos como sinônimos entre si e sinônimos de experiência nos três dicionários.

Enquanto que nos outros dicionários a experimentação é apenas o ato ou efeito de experimentar, o Aurélio comporta um maior esclarecimento: "Método científico que consiste em 
observar um fenômeno natural sob condições determinadas que permitem aumentar o conhecimento que se tenha das manifestações ou leis que regem esse fenômeno".

Nos três dicionários define-se experimento semelhantemente: "Ensaio científico para a verificação de relações entre fatos bem definidos" (Michaelis), "Experiência (principalmente falando de ensaios e estudos científicos)" (Houaiss) e "Ensaio científico destinado à verificação de um fenômeno físico" (Aurélio).

Os dicionários reservam definições outras para os quatro verbetes pesquisados, por exemplo, experimentar como "sentir, sofrer, suportar" (Michaelis). No entanto, consideramos relevantes para este trabalho somente as pertencentes a um dos seguintes domínios:

- Domínio prático: experiência do senso comum, vivência, produto do contato intenso e frequente com aspectos da realidade, levando ao conhecimento, ao domínio, ao adestramento;

- Domínio filosófico: empirismo, como crença na aquisição do conhecimento através dos dados do real, mediado pelos sentidos;

- Domínio da atividade científica: experimentação, experiências ou experimentos como constituintes da atividade de investigação científica, destinados à observação/verificação de fenômenos/leis, sujeitos a determinadas regras (métodos científicos).

Assim, caracterizamos as palavras experiência, experimentar, experimentação e experimento como possuidoras de diversos conteúdos semânticos, e que podem ser enquadrados nos três domínios acima, constituindo como que sua estrutura.

Analisamos a palavra experimentação enquanto categoria abstrata, debruçando-nos sobre sua significação, de acordo com Voloshinov. Se desejarmos algum avanço no conhecimento, à análise deve seguir-se a síntese. Esta, abastecida com o estudo histórico a ser apresentado na próxima seção, permitirá uma aproximação dos possíveis temas da palavra experimentação, conforme utilizados durante a história do ensino de ciências.

\section{Da experimentação na ciência à experimentação no ensino de ciências}

Enquanto constituinte do ensino de ciências, a experimentação atravessou diversos momentos, assumindo diferentes características e finalidades, sendo possível explorá-las a partir dos domínios semânticos identificados acima. Veremos que a emergência de cada uma de suas modalidades, paradigmáticas em seus respectivos contextos históricos, foi acompanhada do preenchimento de diferentes conteúdos nesses domínios semânticos.

\section{"Pré-história" da experimentação no ensino de ciências: experimentação na ciência}

Logicamente, a atividade experimental só passa a ser considerada desejável e relevante para o ensino das ciências após a própria ciência vir a utilizá-la. Nosso ponto de partida, portanto, é a gênese do que chamamos de domínio da atividade científica, na caracterização semântica de palavras como experiência e experimentação. Para Pinho Alves (2000), isso se deu a partir da necessidade de se transcender a doxa (opinião) em direção à episteme (conhecimento), quando o homem adota um proceder premeditado e circunstanciado diante dos fatos, transmutando sua natureza bruta. Estabelece-se, assim, o "diálogo experimental", para que se apreenda o mundo conforme situações mais simples, generalizantes e universais.

Atribui-se a três nomes a fundação dessa ciência moderna: Francis Bacon (1561-1626), René Descartes (1596-1650) e Galileu Galilei (1564-1642).

O Novum organum de Bacon busca superar o antigo método indutivo-dedutivo de Aristóteles, declarando apenas a indução como via para o conhecimento da natureza. Tal posição pressupõe a possibilidade de generalização a partir de proposições de observação singulares (Chalmers, 1993), fortalecendo uma concepção de ciência como dominadora/reveladora da natureza e de suas leis (Hodson, 1988).

Descartes, iniciador do racionalismo moderno, também se opôs a Aristóteles, mas contrariamente a Bacon: pela subordinação dos dados dos sentidos à atividade puramente intelectual como caminho para a descoberta da verdade. Por que essa recusa inicial, por que desconfiar do que os olhos podem ver, do que as mãos podem tocar? Hirschberger (1957), falando sobre a filosofia de Platão, explica que a percepção sensível é incerta, dado que nossos sentidos frequentemente se enganam, experimentando as coisas diferentemente do que elas são; além disso, no mundo dos sentidos impera o devir, em que nada permanece, sendo que os conceitos de verdade e de ciência exigem o que é continuamente idêntico a si.

Decerto, o racionalismo de Descartes tem seu embrião no pensamento de Platão. Mesmo a ideia de um mundo matematicamente estruturado, em que são válidas as rigorosas regras do número e da qual Descartes é partidário, já está presente no discurso do filósofo ateniense. Mas, ao contrário deste, Descartes não despreza totalmente os dados da percepção: "a experiência fica subordinada à razão, na medida em que se reduz, praticamente, a uma função comprovatória. A experiência se faz presente, quando solicitada, caso contrário é dispensável" (Pinho Alves, 2000, p. 181). Como o exercício da função comprobatória da experiência só é possível caso se disponha, a priori, de uma proposição geral cuja validade para um caso particular se deseja verificar, diz-se que o método cartesiano é dedutivo.

Finalmente, encontramos a influência de Platão também em Galileu, que completa o ataque à filosofia aristotélica no século XVII, junto de Bacon e Descartes (Giordan, 1999). Koyré (1991), entretanto, caracteriza seu trabalho como tendo objetivos e alcances ainda mais audaciosos: para Galileu, era imperioso "destruir" um mundo antigo e substituí-lo por um novo, reformando-se a estrutura de nossa própria inteligência, 
encarando o Ser de uma nova maneira e reelaborando os conceitos de conhecimento/ciência. Com isso, operar-se-ia a completa substituição do ponto de vista do senso comum, bastante natural, por outro que, absolutamente, não o é. Essa reestruturação do mundo teve de contemplar:

- A substituição do conceito de Cosmo, como todo finito e hierarquicamente organizado atendendo a princípios de ordem e virtude, pelo conceito de Universo, um sistema de causas e efeitos cuja estrutura é matemática;

- Como consequência, a matematização (geometrização) da natureza e, por conseguinte, da própria ciência;

- A fusão da física sideral com a terrestre, impossível para Aristóteles, para quem o mundo celeste era até mesmo composto de uma essência diversa;

- A equivalência entre o status ontológico do movimento e o do repouso, em que ambos passam a ser estados. Na física de Aristóteles, o movimento é tido como um processo, um devir, e o repouso é o fim do movimento;

- Finalmente, o tratamento do real pelo impossível (o ser real pelo matemático).

Parece suficiente nosso passeio pelas obras de filósofos e historiadores da ciência para determinar o momento em que palavras como experiência e experimento passaram compor o vocabulário científico de um modo novo, provocando o surgimento do domínio semântico da atividade científica para essas palavras.

Antes do aparecimento de diversos personagens, que representamos por Bacon, Descartes e Galileu, a única experiência requisitada para o conhecimento científico é o senso comum. Com o advento da ciência moderna, essa experiência passa a ser encarada como insuficiente ou até indesejável. Já não basta o uso da experiência e dos experimentos quando considerado apenas o que chamamos de domínio prático, quanto à semântica dessas palavras.

O que chamamos de domínio filosófico passa a guiar a concepção de um método científico por Bacon. Descartes e Galileu, opositores deste empirismo-indutivismo, creditam a uma via oposta - matemático-dedutiva - a possibilidade da elaboração de uma episteme.

Vale dizer que, apesar da tendência à oposição do pensamento de Bacon ao de Descartes e Galileu, nenhuma das correntes pode tomar para si a responsabilidade por oferecer um verdadeiro método para o progresso do conhecimento. Sobre a relativização desse contraste, é preciso lembrar que a ciência do século XVII foi, simultaneamente, galileana/baconiana/cartesiana - suas categorias principais, como teoria/experimento, necessidade/contingência e simplicidade/universalidade estão contempladas em todas essas tradições, apesar de suas perspectivas metafísicas serem divergentes ou opostas (Rossi, 1992).

\section{Momentos iniciais da experimentação no ensino de ciências}

Pena (2000), Pinho Alves (2000) e Gonçalves (2005), buscando localizar o momento em que a experimentação começa a ser requisitada nos cursos de ciências, informam que essa demanda já se faz presente a partir do século XVIII, na Europa - logo após a gênese da ciência moderna. Os autores mencionam ainda a importância das universidades para isso: o ensino superior, incluindo os experimentos científicos na formação acadêmica, cria o modelo de laboratório científico para as escolas secundárias.

Conforme a tipologia proposta por Pinho Alves (2000), os laboratórios didáticos mais característicos desse período são o de demonstrações e o tradicional. No primeiro, o executor das atividades experimentais é o próprio docente, cabendo aos alunos observar. Já no laboratório tradicional o professor supervisiona os alunos com a intenção de que desenvolvam uma investigação científica propriamente dita, ainda que, na realidade, a atividade não demande muito mais que seguir instruções de um roteiro.

Tais concepções de laboratório se conformam ao que Saviani (2012a) define como pedagogia tradicional, em que a escola se apresenta como agência centrada no mestre e transmissora da cultura aos alunos. Ainda, o autor explicita a filiação dessa pedagogia à filosofia empirista, dado que sua matriz teórica remonta aos cinco passos formais de Herbart: preparação, apresentação, comparação/assimilação, generalização e aplicação. Tais etapas emulam o método indutivo de Bacon, assentado em três momentos fundadores: observação, generalização e confirmação. ${ }^{2}$

Assim, experimento demonstrativo possui uma função ilustrativa, auxiliar, de realização facultativa (Pinho Alves, 2000). A demonstração do professor à classe se caracteriza, portanto, como um recurso retórico do mestre, diante da dificuldade em transmitir o fato científico - confirmando a vocação empirista desse tipo de experimento, como se os fatos falassem por si. Pinho Alves (2000) menciona também a função motivadora da demonstração experimental, que pode ocorrer no início da exposição visando despertar a atenção da classe para dado assunto. Também quanto a isso a demonstração se compatibiliza com o ensino tradicional, que se relaciona com o conceito de motivação extrínseca, fortemente dependente das características pessoais do professor (Mizukami, 1986).

Sobre o laboratório tradicional, nossas considerações são semelhantes, e a possibilidade de os alunos executarem os experimentos, desejando atingir um resultado pré-determinado como correto pelo professor conforme um roteiro, não muda sua orientação empirista. Tampouco influencia no caráter retórico do experimento tradicional, agora tratado como verificador de teorias: serve à validação do discurso proferido pelo mestre.

Voltemos então a pensar em termos dos domínios semânticos envolvidos nas palavras experimentação, experiência e experimento, nos contextos dos laboratórios de demonstrações e tradicional. Para ambas as situações, o domínio semântico filosófico - empirismo - é afirmado no significado dessas palavras, devido às próprias características do ensino tradicional. O domínio prático também comparece: no laboratório de demonstrações, como 
experiência do senso comum, dado da realidade; no laboratório tradicional, mais como prática, vivência, habilidade em lidar com os instrumentos e procedimentos envolvidos na atividade experimental. Quanto ao domínio da atividade científica, podemos identificá-lo no experimento do laboratório tradicional, mas com ressalvas. Esse experimento não é mais que uma versão simplificada e distorcida do trabalho científico, levando ao que Arruda e Laburú (1998) chamam de imagem tradicional ou popular da ciência e teses indutivistas-verificacionistas, ou o que Chalmers (1993) denomina como indutivismo ingênuo.

Segundo Pena (2000), a abordagem tradicional da experimentação didática prepondera no Brasil e em outros países até meados do século XX. Isso não quer dizer que, da década de 1950 em diante, as demonstrações e o laboratório tradicional desapareceram das escolas, mas que, desde então, eles puderam conviver com novas propostas. A estas, dedicamos as subseções a seguir.

\section{A era dos projetos curriculares}

É praticamente lugar-comum, nos trabalhos da área de Educação em Ciências, tratar da chamada era dos projetos curriculares, reflexo de um momento de renovação no ensino de ciências liderado pelos Estados Unidos e pela Inglaterra a partir do final dos anos 1950. De fato, foi com esse movimento que tal área começou a se constituir.

Não recontaremos essa história em pormenores nem exploraremos exaustivamente seu pano de fundo e suas repercussões. Outros trabalhos já realizaram essa tarefa, entre eles muitos dos que nos auxiliarão nos próximos parágrafos. No entanto, não será possível prosseguir sem mais uma breve reconstituição desse marcante período.

O contexto dos anos seguintes à Segunda Guerra Mundial é o de um mundo dividido: de um lado, o capitalismo, tendo os Estados Unidos como expoente; de outro, o socialismo, representado pela União das Repúblicas Socialistas Soviéticas. Buscando reverter a supremacia científico-tecnológica demonstrada pelo bloco soviético (cujo epítome foi o lançamento do primeiro satélite artificial, o Sputnik I, em 1957), o governo estadunidense propõe medidas econômicas e educativas, repercutindo em um movimento de reforma que elabora os mencionados projetos curriculares (Pórlan Ariza, 1998; Fracalanza, 2006).

Tal reforma curricular legou-nos um ensino de ciências visto como necessidade para a formação do cidadão; o nascimento de áreas de investigação (sobre a estrutura do conteúdo das disciplinas científicas, sobre os objetivos do ensino de ciências, sobre a efetividade de novas abordagens instrucionais, sobre a aprendizagem dos alunos, entre outras); a constituição dos primeiros grupos de pesquisa sobre ensino de ciências, ainda que influenciados por visões positivistas; a difusão da ideia de um currículo em espiral; e uma concepção de ensino aliando teoria/prática e crítica à abordagem tradicional (Krasilchik, 1987; Schnetzler; Aragão; 1995).
Interessa-nos, sobre a filosofia que orientou a elaboração dos projetos, a noção de que era possível e necessário, mais do que ensinar conteúdos, ensinar sobre ciências. Entra em cena, então, o laboratório científico, dessa vez não como recurso acessório, complementar, retórico, mas como protagonista. Se é preciso ensinar sobre ciência, que se faça do aluno um "mini cientista", trabalhando em um laboratório adequadamente equipado. Só assim ele poderá praticar o método científico para realizar descobertas, ou melhor, redescobertas.

Sobre essa que consideramos outra modalidade de atividades experimentais para o ensino de ciências, Amaral (2006) diz se tratar de um método indutivo que propunha um receituário de procedimentos - a encarnação de um "método científico" - de modo a que aluno redescobrisse, com segurança e precisão, os conhecimentos previstos nos currículos oficiais. Para Schnetzler e Aragão (1995, p. 29), os projetos curriculares acabaram mitificando esse "método todo poderoso que leva à descoberta das verdades científicas através de observações objetivas e neutras". Ignorando outras possíveis formas de obtenção do conhecimento, o que se fez foi adaptar o método baconiano para a realidade escolar.

Muitas críticas já foram dirigidas ao método da redescoberta, tratando de sua ineficácia para a aprendizagem a sua coadunação com uma imagem popular de ciência (Pinho Alves, 2000). Importa-nos, sobretudo, ressaltar a característica mais paradoxal dessa proposta: visando superar o ensino tradicional e a passividade dos alunos mesmo quando executores de experimentos em um laboratório estruturado, os projetos curriculares aprofundaram a orientação empirista-ingênua das demonstrações e do laboratório tradicional, consolidando-a com a noção de um método científico infalível. Mesmo (supostamente) empreendendo investigações e se portando como cientista, o aluno permanecia visto como "tábula rasa".

Portanto, do ponto de vista dos domínios semânticos das palavras experimentação, experiência e experimento, as inovações pretendidas pelos projetos curriculares estadunidenses/ ingleses buscavam minimizar, no domínio prático, o componente da experiência do senso comum. O "mini cientista", futuro cientista ou engenheiro, precisa analisar criticamente as informações fornecidas pelos sentidos, sabendo extrair delas as leis ou princípios universais e necessários que governam a natureza. O domínio prático, como no caso do laboratório tradicional, também está relacionado ao treinamento, ao adestramento das habilidades manuais, exigidas para uma postura adequada frente a um experimento didático; o aluno não é mais um receptor passivo de conteúdos, mas empenha-se em busca de uma redescoberta. Esta só será possível guiando-se pelo método científico, apresentado como uma transposição do método de Bacon para situações didáticas. Daí a forte presença do domínio filosófico na semântica da palavra experimentação nesse contexto. Finalmente, o domínio da atividade científica também aparece fortemente pronunciado e, como no caso do laboratório tradicional, sua visão de ciência é a mesma visão 
ingênua veiculada pelos dicionários: a ciência observa/verifica fenômenos/leis, através de um método universalmente válido.

Antes de prosseguir, vamos nos deter rapidamente em um aspecto de algumas das propostas difundidas nos anos $1960 \mathrm{e}$ 70 , no seio dos projetos curriculares: a influência da psicologia comportamental.

O comportamentalismo (ou behaviorismo) se desenvolveu no início do século XX procurando entender os elos entre os estímulos fornecidos a um indivíduo e suas respostas diante deles. Seus estudos levaram ao reconhecimento do potencial das chamadas contingências de reforço (conforme Mizukami (1986), as relações entre a ocasião em que uma resposta ocorreu, a própria resposta e as consequências reforçadoras dessa reposta) para objetivos educacionais. A teoria comportamentalista educacional mais conhecida entre os professores é provavelmente a de Skinner, que iniciou um movimento de pesquisa e criação de tecnologias de ensino, culminando no princípio da instrução programada.

Pinho Alves (2000) exemplifica um projeto para o ensino de ciências característico dessa abordagem: o Projeto Piloto para o Ensino de Física, elaborado no Instituto Brasileiro de Educação, Ciência e Cultura (IBECC) entre 1963 e 1964. Para o autor, tal iniciativa foi inovadora e audaz: inovadora porque, até então, nenhuma proposta brasileira para o ensino de ciências havia adotado a instrução programada; audaz, por conta da limitação de conhecimento e experiência sobre esse novo método, que implicava a produção de um material autossuficiente.

O motivo desta digressão pela análise da influência comportamentalista nas propostas didáticas é seu caráter inovador, como o autor acima ressalta. Pela primeira vez, a pesquisa em Psicologia inspirava iniciativas concretas em prol do ensino, inclusive, constituindo uma disciplina própria, a Psicologia da Aprendizagem, que logo se tornaria um terreno de disputas e debates entre diferentes teorias. Como veremos, o que marcará grande parte das diferenças entre as modalidades de atividades experimentais para o ensino de ciências, daqui por diante, será a orientação psicológica adotada como referencial.

Não podemos deixar de mencionar que a abordagem comportamental se ajusta perfeitamente aos pressupostos epistemológicos da concepção dos projetos curriculares estadunidenses, dada sua ênfase empirista. Segundo Mizukami (1986), em tal perspectiva há o primado do objeto, o conhecimento é considerado como descoberta para o indivíduo e cópia de algo dado no mundo externo, sendo a ciência uma tentativa de se descobrir a ordem na natureza - todos pressupostos compartilhados pelo empirismo. Ainda, pode-se considerar essa concepção psicológica como o fundamento de um entendimento particular sobre o ensino, a chamada pedagogia tecnicista.

\section{A virada cognitivista}

Como visto, nos anos 1960, as propostas para a renovação do ensino de ciências se dão no embate científico-tecnológico entre superpotências, no âmbito internacional.
No Brasil, a necessidade de modernização da estrutura socioeconômica, levando à industrialização e à urbanização, dirige a promulgação da Lei de Diretrizes e Bases da Educação Nacional - Lei no 4.024/61 (Krasilchik, 2000). A flexibilização dos currículos amplia a carga horária das disciplinas científicas, incentivando propostas de inovação (Krasilchik, 2000; Pena, 2000; Fracalanza, 2006).

Após o golpe de 1964, aprofunda-se o processo de internacionalização da economia brasileira e, dentro da política desenvolvimentista, os princípios da racionalidade técnica são incorporados à reforma da LDB, consubstanciada na Lei no 5.692/71. Buscando atender à profissionalização do ensino médio, tornada obrigatória por essa lei, em 1972 o Programa de Expansão e Melhoria do Ensino, órgão do Ministério da Educação e Cultura para executar parte dos acordos MECUSAID, criou o Projeto Nacional para a Melhoria do Ensino de Ciências, financiando 12 novos projetos curriculares até 1978 (Fracalanza, 2006).

Se no Brasil, durante os anos 1970, o paradigma tecnicista vive seu auge, no âmbito internacional observam-se sinais de esgotamento. A degradação ambiental, agravada pelo uso desenfreado dos recursos naturais com a industrialização e o consumismo, força à reflexão sobre a sustentabilidade, questionando a própria noção de progresso científico. Debate-se a natureza do empreendimento investigativo, a neutralidade da ciência e a necessidade de critérios de demarcação entre conhecimento científico e senso comum. A redescoberta de duas obras da década de 1930 (A lógica da descoberta científica, de Karl Popper, e A formação do espírito científico, de Gaston Bachelard), mais os livros cruciais de Thomas Kuhn (A estrutura das revoluções científicas), Imre Lakatos (O falseamento e a metodologia dos programas de pesquisa científica) e Paul Feyerabend (Contra o método), põem em xeque a concepção da ciência como superior a outros conhecimentos, por ser verdadeira e imutável, por operar sob a rigidez de um método e por não ser determinada por fatores históricos de ordem econômica, social, psicológica, ideológica.

Nas ciências humanas, incluindo o emergente campo da Educação em Ciências, o enfoque positivista começa a ser preterido em favor de perspectivas fenomenológicas e estruturalistas. As investigações passam a empregar metodologias qualitativas (em detrimento dos métodos estatístico-quantitativos), levando em conta também as contribuições da psicologia cognitivista (Schnetzler; Aragão, 1995), cujo processo de ascensão é atribuído por Krasilchik (1987) a dois eventos: o primeiro, a publicação da obra de Bruner, $O$ processo da educação, a partir de uma conferência ocorrida em 1959; e o segundo, as conferências realizadas em 1964 nas Universidades de Cornell e Califórnia, denominadas Piaget redescoberto, abrangendo estudos cognitivos e desenvolvimento de currículos, sob a consultoria do próprio Jean Piaget. Ainda de acordo com Krasilchik, por algum tempo haveria a convivência entre as propostas didáticas advindas do comportamentalismo e a 
chamada abordagem cognitivista do ensino, conforme nomeia Mizukami (1986).

Para esta última autora, o cognitivismo se refere à investigação de "processos centrais" do indivíduo, como organização do conhecimento, processamento de informações, tomada de decisões etc. - formas como as pessoas lidam com estímulos e dados, resolvem problemas, adquirem conceitos e empregam símbolos verbais. Para Mizukami, embora se notem preocupações com a socialização, a ênfase de tais estudos recai sobre as capacidades individuais dos alunos. Assim, ao contrário das abordagens tradicional e comportamentalista, a abordagem cognitivista não centra suas atenções no objeto, no exterior, mas na interação entre este e o sujeito cognoscente - daí a referência a tal abordagem como interacionista. O principal representante da psicologia cognitivista, num primeiro momento, é Jean Piaget. ${ }^{3}$

A teoria piagetiana considera o indivíduo como um sistema aberto, cujas reestruturações sucessivas o conduzirão a um estágio com grau máximo de operacionalidade (motora, verbal ou mental), possibilitado por um processo espontâneo, apesar de contínuo e laborioso. A aquisição de conhecimento resulta da ação do sujeito; o objetivo da educação "não consistirá na transmissão de verdades, informações, demonstrações, modelos etc., e sim em que o aluno aprenda [...] a conquistar essas verdades, mesmo que tenha de realizar todos os tateios pressupostos por qualquer atividade real" (Mizukami, 1986, p. 71).

Tal concepção traz profundos impactos para as atividades experimentais didáticas. Ao mesmo tempo em que perdem centralidade (já que qualquer tarefa que instigue, estimule e desafie o estudante passa a ser desejável), cedendo lugar a estratégias como jogos, projetos e discussões, as funções do laboratório didático são repensadas: passa-se a encarar o laboratório como ativador do progresso pelos períodos de desenvolvimento do aluno ou como espaço para aferição de seu atual período (Krasilchik, 2000). Nesse sentido, propõe-se que as experiências não sejam feitas diante dos estudantes, nem sejam elaboradas ou propostas por guias externos, mas pelos próprios escolares, já que a autonomia intelectual e a pesquisa seriam alavancas para a promoção de novas noções e operações mentais (Mizukami, 1986).

No início dos anos 1980 a influência cognitivista já está estabelecida no campo da Educação em Ciências. O construtivismo, termo que passou a ser associado aos diversos autores de linha mais cognitivista, incluindo Piaget, se transforma em um ideal para o ensino, permeando o discurso dos educadores com slogans aceitos mais ou menos criticamente.

Proliferam-se as pesquisas sobre os conhecimentos prévios dos estudantes, constituindo o movimento das concepções alternativas. A mobilização desses novos resultados visando uma melhor aprendizagem das ciências se consolida no modelo de mudança conceitual, em que são pensadas estratégias para que os alunos substituam tais conceitos prévios pelo conhecimento científico.
Quanto à importância da experimentação no ensino de ciências, a comunidade de especialistas se engaja em um movimento de avaliação e elaboração de novas propostas. Examinemo-las sob a óptica dos domínios semânticos das palavras experimentação, experiência e experimento. A virada cognitivista assinala a perda de ênfase no domínio prático, tanto sob o aspecto da experiência do senso comum (a ser superada pelo conhecimento científico), quanto do aspecto da manipulação, pois o treinamento das habilidades motoras é tomado como resultado secundário, se bem que não indesejável. O domínio filosófico, abrigando a componente empirista, também passa a ser visto como superável. A reorientação epistemológica das ciências considera que não é senão à luz de teorias que as observações permitem o conhecimento. Finalmente, sobre o domínio da atividade científica, observa-se pela primeira vez uma visão de ciência menos ingênua, dogmática, neutra e a-histórica; considera as discussões da nova filosofia da ciência e reconhece a diferença entre a ciência dos cientistas e a ciência a ser ensinada.

\section{Implicações para a pesquisa e para as práticas pedagógicas}

Ao longo da seção anterior, traçamos um histórico da experimentação como estratégia para o ensino dos conteúdos científicos. De uma aceitação acrítica do pressuposto de que "se a ciência é realizada nos laboratórios, a ciência deve ser ensinada através dos laboratórios", passou-se a admitir que a atividade experimental não é a única estratégia para um ensino de ciências eficiente. As contribuições do cognitivismo no campo da Educação em Ciências levaram ao reconhecimento de que os alunos estruturam espontaneamente sua experiência cotidiana assimilando-a a seus esquemas conceituais. Resultam daí as concepções alternativas, que podem ser tanto facilitadoras quanto obstáculos para o alcance do conhecimento. Visando lidar com a complexidade do funcionamento da mente do aprendiz, foram elaboradas estratégias para orientá-lo a "pensar lógica e criticamente" - o que se tornou um ideal do ensino de ciências (Krasilchik, 1987). Muitas dessas estratégias significaram um abandono do laboratório didático, cuja serventia foi questionada por pesquisas que evidenciaram seus limites e seu potencial em veicular visões distorcidas (principalmente, indutivistas ingênuas) sobre o empreendimento científico. Por outro lado, pesquisadores e professores continuaram a perseguir o objetivo de tornar o laboratório um local de aprendizado e envolvimento com a ciência, fundamentando suas propostas nos resultados do já consolidado campo da Educação em Ciências e determinando o nascimento de novas modalidades para a experimentação, como os experimentos investigativos.

Sintetizando essas ideias, expomos no Quadro 2 como entendemos que se constituiu historicamente o conceito de experimentação no ensino de ciências, até a forma como os especialistas o compreendem atualmente. 
Quadro 2: períodos e/ou modalidades da experimentação no ensino de ciências e conteúdos dos domínios semânticos das palavras experimentar, experimentação, experiência e experimento.

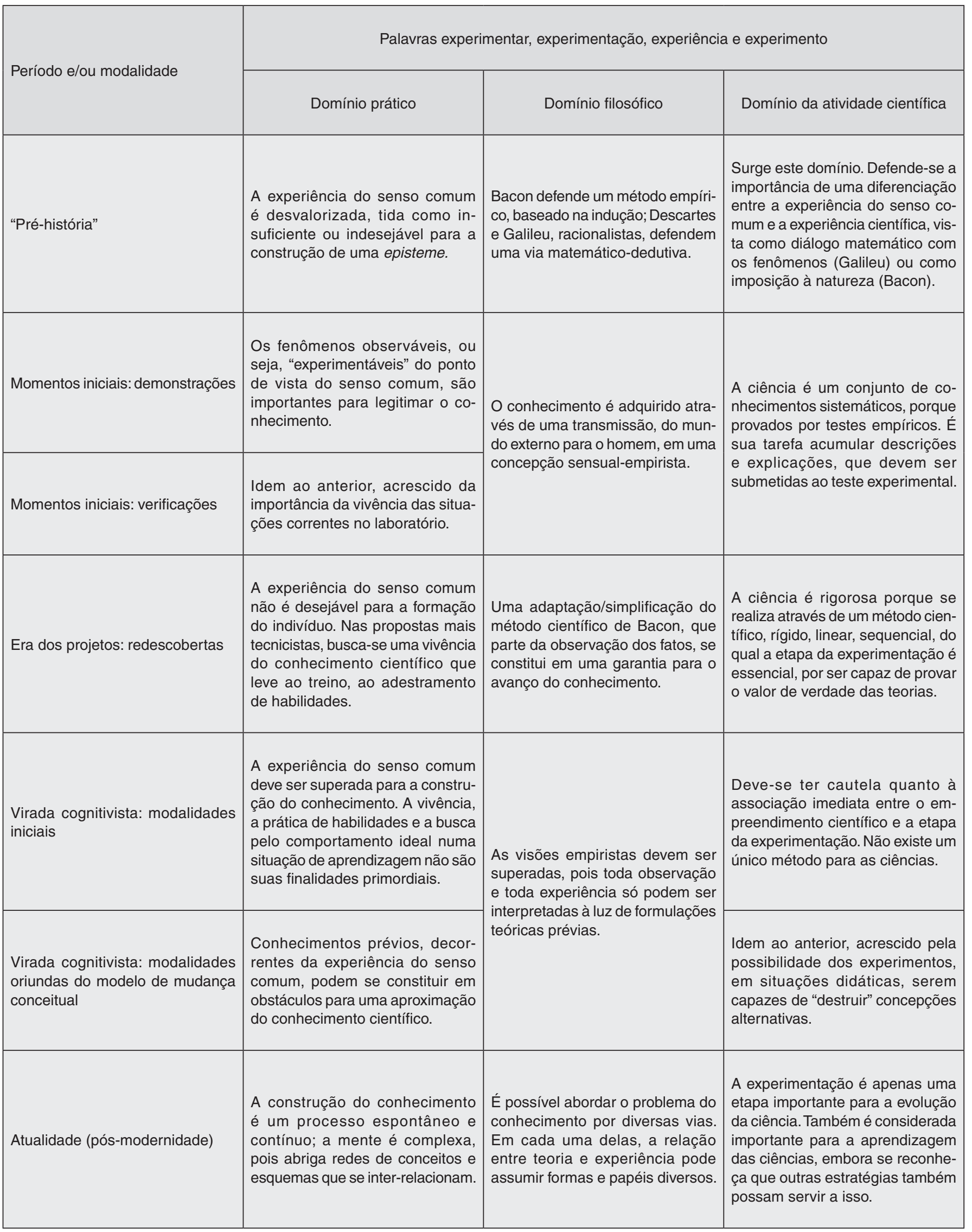


O quadro pode ser explicado resumidamente desta maneira: ao longo da história das ciências e de seu ensino, a palavra experimento (e suas derivações) expressou diferentes temas ou sentidos conforme a situação histórica em que fosse enunciada. Os dicionários são incapazes de registrar esses temas; no fogo cruzado da contradição entre o aspecto uno e múltiplo das palavras, eles apenas registram os caracteres mais fundamentais delas, para permitir que continuem sendo mobilizadas em novas trocas discursivas.

No entanto, tomando-se os verbetes dicionarizados como material empírico, é possível nos aproximarmos dos temas mais típicos ou característicos de dados momentos históricos - na tentativa de fazer, portanto, uma paleontologia das significações linguísticas, nos termos do próprio Voloshinov, para quem "a palavra [...] reflete sutilmente as mais imperceptíveis alterações da existência social" (Bakhtin, 2004, p. 46). Entendemos que, mais do que "refletir sutilmente", estamos diante de palavras experiência, experimento, experimentação, experimentar - em que esses temas se cristalizaram, possibilitando a emergência, nos tempos atuais, da polissemia a que nos referimos no título deste trabalho.

Assim, foi possível observar uma estrutura para as palavras que examinamos, constituída pelo que chamamos de domínios semânticos. A cada momento histórico do ensino de ciências, esses domínios - domínio prático, domínio filosófico e domínio da atividade científica -, preenchidos por diferentes conteúdos objetivos, perfizeram concepções igualmente diferentes acerca do papel da experimentação didática.

Note-se que, a despeito do uso do termo estrutura, nossa perspectiva não se filia a nenhum tipo de estruturalismo, até porque os domínios semânticos identificados não se apresentam como estruturas universais e necessárias dessas palavras, pelo contrário, são históricos. Ao mesmo tempo, a história do uso dessas palavras tem levado a diferentes valorações a respeito desses domínios - fosse pela reafirmação, pela negação ou pelo silenciamento, como expusemos ao longo do artigo.

Encerramos a confecção do quadro na linha referente ao período atual, que corresponderia à vigência do ideário pós-moderno no campo da educação. Os três domínios semânticos dessa última linha estão preenchidos por conteúdos que remetem ao relativismo e ao pluralismo metodológico no ensino e na natureza das ciências. Na verdade, eles apenas aprofundam os conteúdos das duas linhas imediatamente anteriores, que assinalam a "virada cognitivista" na educação científica, quando o construtivismo começa a se estabelecer enquanto seu principal referencial.

Para Duarte (2006), existe uma íntima relação entre o construtivismo e o ideário pós-moderno; este seria, em verdade, o fundamento das chamadas "pedagogias do aprender a aprender", entre as quais podem ser incluídas as correntes construtivistas e também a pedagogia dos projetos, a pedagogia das competências, a pedagogia do professor reflexivo e a pedagogia multiculturalista. Saviani (2013), endossando as análises de Duarte, referir-se-á a um conjunto de pedagogias neoprodutivistas, cujas bases didático-pedagógicas se orientam por esse aprender a aprender e que, no atual momento da história das ideias pedagógicas no Brasil, são as tendências hegemônicas.

Analisando a primeira coluna do Quadro 2, observa-se que, em todos os períodos mencionados, as pedagogias que sustentam as concepções sobre a experimentação (pedagogia tradicional, pedagogia tecnicista, construtivismo) se inserem junto à tradição hegemônica - no caso, de matiz liberal. Segundo Libâneo (1988), tal entendimento sobre educação inspira-se na doutrina do liberalismo econômico que, defendendo a predominância da liberdade e dos interesses individuais, busca justificar a organização social capitalista, fundada na propriedade privada dos meios de produção.

Contraditoriamente, é preciso reconhecer que, além de contribuir para a consolidação do campo da Educação em Ciências, dotando-o de cientificidade e de um programa de pesquisa claro, essa tradição liberal abrigou dezenas de pesquisadores cujos estudos e atividades profissionais viriam também a questionar a própria sociedade capitalista. Sob a influência desses estudiosos, novas produções viriam a fortalecer correntes pedagógicas com um discurso nitidamente de esquerda, contrapondo-se explicitamente aos fundamentos do atual modo de produção. Inclusive, viriam a se somar, na militância em prol dessas pedagogias, alguns dos antigos defensores da tradição liberal.

Ora, cabe então perguntar se há a possibilidade de concepções sobre a experimentação no ensino alinhadas a essas pedagogias, agrupadas sub diversas terminologias - progressistas (Libâneo, 1988), críticas (Saviani, 2012a) ou contra hegemônicas (Saviani, 2013). Nesse caso, no lugar de nomes como Herbart (pedagogia tradicional), Skinner (pedagogia tecnicista) ou Piaget (construtivismo), outras concepções sobre a experimentação poderiam recorrer a Paulo Freire (pedagogia libertadora), Célestin Freinet (pedagogia libertária), José Carlos Libâneo (pedagogia crítico-social dos conteúdos) ou Dermeval Saviani (pedagogia histórico-crítica).

Diante dessa situação, a questão que se impõe é: de que maneira os educadores poderiam reunir elementos teóricos para fundamentar as atividades experimentais didáticas conforme essas pedagogias contra hegemônicas?

Acreditamos que a resposta para tal questão repouse no estudo dos domínios semânticos que identificamos em nosso trabalho. Assim, o problema estaria posto nos seguintes termos:

- Como uma pedagogia contra hegemônica lida com as questões da prática do senso comum e do adestramento manual, relacionadas ao domínio prático?

- Como ela lida com a concepção do empirismo sensualista associada ao domínio filosófico?

- E qual sua concepção sobre a natureza da ciência, conteúdo do domínio da atividade científica?

Pensamos que, a partir de tais questões, possa se desdobrar uma agenda de pesquisa, preocupada com a elaboração do conceito de experimentação conforme outras tendências 
pedagógicas ainda carentes de divulgação e aprofundamento, por parte de nós, educadores em ciências.

A bem da verdade, esse trabalho já foi iniciado e, a despeito de seu desenvolvimento ainda incipiente em nosso território, a literatura já registra contribuições promissoras. Por exemplo, o trabalho de Francisco Junior, Ferreira e Hartwig (2008) apresenta a proposta de uma experimentação problematizadora, que se erige a partir de elementos dos experimentos investigativos, mas procura superá-los com uma fundamentação teórica explicitamente freireana. Já em uma direção mais próxima à pedagogia histórico-crítica, o trabalho de Camillo (2011) procura na psicologia histórico-cultural - associada principalmente aos nomes de Vigotski e Leontiev - os fundamentos da experimentação enquanto uma atividade de ensino-aprendizagem mediada por instrumentos. Tal desenvolvimento dá continuidade, de certa forma, ao trabalho de Gaspar (2006), um dos pioneiros, no Brasil, ao pensar a experimentação didática a partir da teoria vigotskiana.

A legitimidade - e a necessidade - desse tipo de investigação é atestada, novamente, pelo próprio Voloshinov. Como dissemos, existem diferentes vozes que ressoam na palavra experimentação, contribuindo para seu caráter polissêmico. No entanto, apesar dos conflitos existentes entre essas vozes, que expusemos ao longo do artigo, todas aparecem alinhadas - como se cantassem a mesma canção, ainda que em contraponto. É possível, no entanto, acrescentar vozes dissonantes a essa sinfonia, afinal

A classe dominante tende a conferir ao signo ideológico um caráter intangível e acima das diferenças de classe, a fim de abafar ou de ocultar a luta dos índices sociais de valor que aí se trava, a fim de tornar o signo monovalente.

$\mathrm{Na}$ realidade, todo signo ideológico vivo tem, como Jano, duas faces. Toda crítica viva pode tornar-se elogio, toda verdade viva não pode deixar de parecer para alguns a maior das mentiras. Esta dialética interna do signo não se revela inteiramente a não ser nas épocas de crise social e de comoção revolucionária. Nas condições habituais da vida social, esta contradição oculta em todo signo ideológico não se mostra à descoberta porque, na ideologia dominante estabelecida, o signo é sempre um pouco reacionário e tenta, por assim dizer, estabilizar o estágio anterior da corrente dialética da evolução social e valorizar a verdade de ontem como sendo válida hoje em dia. Donde o caráter refratário e deformador do signo ideológico nos limites da ideologia dominante (Bakhtin, 2004, p. 47, grifo do autor).

\section{Considerações finais}

Apesar de ter sido proposta já há quase um século, na Rússia soviética, a filosofia da linguagem expressa na obra de Voloshinov se trata de um referencial atual e profícuo não apenas para a pesquisa linguística e literária, mas também para o campo da Educação. Suas repercussões ainda estão por ser desenhadas, principalmente à luz dos esclarecimentos recentes a respeito dos textos atribuídos a Bakhtin nas últimas décadas, incluindo Marxismo e filosofia da linguagem, e da publicação, no Brasil, de novas traduções de obras do "Círculo de Bakhtin", como A construção da enunciação (Volochínov, 2013) e O método formal nos estudos literários (Medvediév, 2012).

Neste artigo, procuramos mobilizar essa filosofia da linguagem para o entendimento de um conceito da área da Educação em Ciências, a experimentação didática. Como a obra de Voloshinov resgata a historicidade dos signos linguísticos, ressaltando a relação íntima entre tais signos e as práticas sociais em que se situam, conseguimos desvelar aspectos da constituição histórica da experimentação que vieram a se incorporar na significação dessa palavra, remetendo-nos, portanto, aos temas que ajudaram na construção de sua atual polissemia.

Essa polissemia é resultado do conjunto de vozes que, historicamente, passaram a atuar nos enunciados de que a experimentação participa. Buscamos, além de desvelar o caráter dessas vozes, lembrar que elas se filiam a um determinado entendimento sobre educação, a despeito de sua heterogeneidade - fazendo da experimentação uma palavra monovocálica. Entendemos, também, que esse entendimento necessite ser confrontado por sua natureza liberal, na busca por uma educação crítica e transformadora de fato.

Convidamos os estudiosos a contribuírem para que a palavra experimentação, enquanto signo ideológico vivo, e que participa dos enunciados proferidos na área de Educação em Ciências, se torne mais polifônica.

\section{Notas}

1. É importante observar que tal escolha metodológica, partindo da exploração de verbetes em dicionários, mostrou-se suficiente para as análises aqui empregadas. No entanto, caso a pesquisa lidasse com outras palavras, cujo processo de dicionarização ainda não tenha sido capaz de aproximar as categorias significação e tema, teriam de ser eleitos outros caminhos metodológicos, alternativos ou complementares à consulta aos dicionários. Um desses caminhos poderia ser a tomada de depoimentos de sujeitos cujas atividades se relacionem com as palavras investigadas.

2. Consideramos importante ressaltar que a pedagogia tradicional se respalda sim em fundamentos teóricos. Entendemos haver uma espécie de "senso comum pedagógico", fruto de uma insuficiente investigação histórica sobre o fenômeno da educação, que destitui essa pedagogia de suas bases científicas, considerando-a como uma forma espontânea de entendimento sobre o ensino e aprendizagem. Veja-se, por exemplo, a obra 
de Mizukami (1986). Saviani (2012a), por sua vez, ressalta o papel ideológico cumprido por essa compreensão equivocada e incompleta.

3. Outro senso comum pedagógico consiste em se atribuir a Vigotski, e não a Piaget, o título de "psicólogo (sócio) interacionista". O equívoco dessa noção e, novamente, seu papel ideológico, é um dos objetos de investigação/denúncia na obra de Duarte (2006).

4. Talvez o termo "paleontologia" não seja o mais feliz para a caracterização desse processo em que sucessivas camadas de significado se adicionam a uma dada palavra. Afinal, não se trata do ocultamento de camadas mais antigas pela deposição de camadas novas, como no caso do processo de sedimentação. As camadas de significado, diferentemente das camadas sedimentares, ficam como que expostas, manifestas, disponíveis aos enunciadores.

\section{Referências}

AMARAL, I.A. Os fundamentos do ensino de ciências e o livro didático. In: FRACALANZA, H.; MEGID NETO, J. (Org.). O livro didático de ciências no Brasil. Campinas: Komedi, 2006, p. 81-123.

ARAÚJO, M.S.T.; ABIB, M.L.V.S. Atividades experimentais no ensino de física: diferentes enfoques, diferentes finalidades. Revista Brasileira de Ensino de Física, v. 25, n. 2, p. 176-194, 2003.

ARRUDA, S.M.; LABURÚ, C.E. Considerações sobre a função do experimento no ensino de ciências. In: NARDI, R. (Org.). Questões atuais no ensino de ciências. São Paulo: Escrituras, 1998.

BAKHTIN, M.M. Problemas da poética de Dostoiévski. Trad. Paulo Bezerra. Rio de Janeiro: Forense-Universitária, 1981.

BAKHTIN, M.M. (VOLOCHINOV). Marxismo e filosofia da linguagem: problemas fundamentais do método sociológico na ciência da linguagem. $11^{\mathrm{a}}$ ed. Trad. Michel Lahud e Yara F. Vieira. São Paulo: Hucitec, 2004.

BRONCKART, J.P; BOTA, C. Bakhtin desmascarado: história de um mentiroso, de uma fraude, de um delírio coletivo. Trad. Marcos Marcionilo. São Paulo: Parábola, 2012.

CAMILLO, J. Experiências em contexto: a experimentação numa perspectiva sócio-cultural-histórica. 2011. 175 f. Dissertação (Mestrado em Ensino de Ciências), Universidade de São Paulo, São Paulo, 2011.

CEREJA, W. Significação e tema. In: BRAIT, B. (Org.). Bakhtin: conceitos-chave. $5^{\text {a }}$ ed. São Paulo: Contexto, 2012, p. 201-220.

CHALMERS, A.F. O que é ciência, afinal? Trad. Raul Fiker. São Paulo: Brasiliense, 1993.

DUARTE, N. Vigostki e o "aprender a aprender": crítica às apropriações neoliberais e pós-modernas da teoria vigostkiana. $4^{\mathrm{a}}$ ed. Campinas: Autores Associados, 2006.

FERREIRA, A.B.H. Novo Aurélio século XXI: o dicionário da língua portuguesa. $3^{\text {a }}$ ed. Rio de Janeiro: Nova Fronteira, 1999.

FRACALANZA, H. O ensino de ciências no Brasil. In: FRACALANZA, H.; MEGID NETO, J. (Org.). O livro didático de ciências no Brasil. Campinas: Komedi, 2006, p. 125-152.
FRANCISCO JUNIOR, W.E.; FERREIRA, L.H; HARTWIG, D Experimentação problematizadora: fundamentos teóricos e práticos para a aplicação em salas de aula de ciências. Química Nova na Escola, São Paulo, n. 30, p. 34-41, 2008.

FREITAS, M.T.A. O pensamento de Vygotsky e Bakhtin no Brasil. Campinas: Papirus, 1994.

GASPAR, A. A teoria de Vigotski: um novo e fértil referencial para o ensino das ciências. 2006. 192 f. Tese (Livre docência), Universidade Estadual Paulista Julio de Mesquita Filho, Guaratinguetá, 2006.

GIORDAN, M. O papel da experimentação no ensino de ciências. Química Nova na Escola, n. 10, p. 43-49, 1999.

GONÇALVES, F.P. O texto de experimentação na educação em Química: discursos pedagógicos e epistemológicos. 2005. Dissertação (Mestrado em Educação Científica e Tecnológica), Universidade Federal de Santa Catarina, Florianópolis, 2005.

HIRSCHBERGER, J. História da filosofia na Antigüidade. Trad. Alexandre Correia. $2^{\mathrm{a}}$ ed. São Paulo: Herder, 1957.

HODSON, D. Experiments in science and science teaching. Educational Philosophy and Theory, v. 20, n. 2, p. 53-66, 1988.

KOOGAN, A.; HOUAISS, A. Enciclopédia e dicionário: Rio de Janeiro: Delta, 1999.

KOYRÉ, A. Estudos de história do pensamento científico. Trad. Marcio Ramalho. $2^{\text {a }}$ ed. Rio de Janeiro: Forense Universitária, 1991.

KRASILCHIK, M. O professor e o currículo das ciências. São Paulo: EPU, 1987.

Reformas e realidade: o caso do ensino das ciências. São Paulo em Perspectiva, v. 14, n. 1, p. 85-93, 2000.

LEONTIEV, A.N. O desenvolvimento do psiquismo. Trad. Manuel D. Duarte. Lisboa: Horizonte, 1978.

LIBÂNEO, J.C. Democratização da escola pública: a pedagogia críticosocial dos conteúdos. $6^{\text {a }}$ ed. São Paulo: Loyola, 1988.

MARX, K. Contribuição à crítica da economia política. Trad. Florestan Fernandes. 3 reimpr. da 2. ed. São Paulo: Expressão Popular, 2013.

MEDVEDIÉV, P. N. O método formal nos estudos literários: introdução crítica a uma poética sociológica. Trad. Sheila Camargo Grillo e Ekaterina Vólkova Américo. São Paulo: Contexto, 2012.

MICHAELIS: moderno dicionário da língua Portuguesa. São Paulo: Melhoramentos, 1998

MIZUKAMI, M.G.N. Ensino: as abordagens do processo. São Paulo: EPU, 1986.

MORTIMER, E.F.; SCOTT, P. Atividade discursiva nas salas de aula de ciências: uma ferramenta sociocultural para analisar e planejar o ensino. Investigações em Ensino de Ciências, v. 7, n. 3, 283-306, 2002.

PENA, P. A experimentação nos livros didáticos de ciências das séries iniciais do ensino fundamental. 2000. Dissertação (Mestrado em Educação), Universidade Federal de Uberlândia, Uberlândia, 2000.

PINHO ALVES, J. Atividades experimentais: do método à prática construtivista. 2000. Tese (Doutorado em Educação), Universidade Federal de Santa Catarina, Florianópolis, 2000.

PORLÁN ARIZA, R. Pasado, presente y futuro de la didáctica de las ciencias. Enseñanza de las Ciências, v. 16, n. 1, p. 175-185, 1998. 
ROSSI, P. A ciência e a filosofia dos modernos: aspectos da revolução científica. Trad. Álvaro Lorencini. São Paulo: Unesp, 1992.

SAVIANI, D. Escola e democracia. 42a ed. Campinas: Autores Associados, 2012a.

. Marxismo, educação e pedagogia. In: SAVIANI, D.; DUARTE, N. (Org.). Pedagogia histórico-crítica e luta de classes na educação escolar. Campinas: Autores Associados, 2012b.

História das ideias pedagógicas no Brasil. $4^{\mathrm{a}}$ ed. Campinas: Autores Associados, 2013.

SCHNETZLER, R.P.; ARAGÃO, R.M.R. Importância, sentido e contribuições de pesquisas para o ensino de química. Química Nova na Escola, n. 1, p. 27-31, 1995.
VOLOCHÍNOV, V.N. A construção da enunciação e outros ensaios. Organização, tradução e notas de João Wanderley Geraldi. São Carlos: Pedro \& João, 2013.

\section{Para saber mais}

BRANDIST, C. O dilema de Voloshinov: sobre as raízes da teoria dialógica do enunciado. In: (Org.). Repensando o Círculo de Bakhtin. Trad. Helenice Gouvea e Rosemary H. Schettini. São Paulo: Contexto, 2012, p. 35-63.

ZANDWAIS, A. Bakhtin/Voloshinov: condições de produção de Marxismo e filosofia da linguagem. In: BRAIT, B. (Org.). Bakhtin e o Círculo. São Paulo: Contexto, 2009, p. 97-116. 